\title{
Factors associated with postoperative complications and I-year mortality after surgery for colorectal cancer in octogenarians and nonagenarians
}

This article was published in the following Dove Press journal:

Clinical Interventions in Aging

19 May 2016

Number of times this article has been viewed

\section{Young Wan Kim \\ Ik Yong Kim}

Division of Colorectal Surgery, Department of Surgery, Yonsei University Wonju College of Medicine, Wonju, Korea
Correspondence: Young Wan Kim Division of Colorectal Surgery, Department of Surgery, Yonsei University Wonju College of Medicine, 20 Ilsan-ro, Wonju-si, Gangwon-do 26426, Korea

Tel $+823374 I 0573$

Fax +82337410574

Email youngwkim@yonsei.ac.kr
Purpose: To identify the factors affecting 30-day postoperative complications and 1-year mortality after surgery for colorectal cancer in octogenarians and nonagenarians.

Methods: Between 2005 and 2014, a total of 204 consecutive patients aged $\geq 80$ years who underwent major colorectal surgery were included.

Results: One hundred patients were male (49\%) and 52 patients had American Society of Anesthesiologists (ASA) score $\geq 3$ (25\%). Combined surgery was performed in 32 patients (16\%). Postoperative complications within 30 days after surgery occurred in 54 patients $(26 \%)$ and 30-day mortality occurred in five patients (2\%). Independent risk factors affecting 30-day postoperative complications were older age ( $\geq 90$ years, hazard ratio [HR] with $95 \%$ confidence interval $[\mathrm{CI}]=4.95[1.69-14.47], P=0.004$ ), an ASA score $\geq 3$ (HR with $95 \% \mathrm{CI}=4.19$ [1.8-9.74], $P=0.001$ ), performance of combined surgery (HR with $95 \% \mathrm{CI}=3.1[1.13-8.46]$, $P=0.028)$, lower hemoglobin level ( $<10 \mathrm{~g} / \mathrm{dL}$, HR with 95\% CI =7.56 [3.07-18.63], $P<0.001)$, and lower albumin level $(<3.4 \mathrm{~g} / \mathrm{dL}$, HR with $95 \% \mathrm{CI}=3.72$ [1.43-9.69], $P=0.007)$. An ASA score $\geq 3$ (HR with 95\% CI $=2.72$ [1.15-6.46], $P=0.023$ ), tumor-node-metastasis (TNM) stage IV (HR with 95\% CI $=3.47$ [1.44-8.39], $P=0.006$ ), and occurrence of postoperative complications (HR with 95\% CI $=4.42$ [1.39-14.09], $P=0.012$ ) were significant prognostic factors for 1-year mortality.

Conclusion: Patient-related factors (older age, higher ASA score, presence of anemia, and lower serum albumin) and procedure-related factors (performance of combined surgical procedure) increased postoperative complications. Avoidance of 30-day postoperative complications may decrease 1-year mortality.

Keywords: colonic neoplasms, rectal neoplasms, laparoscopy, laparotomy, aged 80 years and above

\section{Introduction}

According to the World Health Organization (WHO) reports, estimated life expectancy at age 60 years was 21.5 years in women and 18.5 years in men in $2012 .{ }^{1}$ As the life expectancy increases, the population of the elderly is also increasing rapidly. Colorectal cancer is the third most common cancer in men and the second most common in women with 1,360,000 newly diagnosed patients worldwide. ${ }^{2}$ Colorectal cancer has a higher incidence in older populations; ${ }^{3}$ accordingly, colorectal surgeons have more frequently encountered octogenarian and nonagenarian patients with colorectal cancer in recent years.

Surgery is the primary treatment modality for colorectal cancer and is performed either with curative intent or for problem solving when patients present with colon perforation 
or obstruction. Chronological aging is closely related to impaired functional status due to medical comorbidities. ${ }^{4}$ Although there is no consensus yet on whether chronological age adversely influences postoperative outcome, there are still concerns for operative safety in octogenarian and nonagenarian patients. To date, a number of studies have reported surgical outcomes in elderly patients; however, heterogeneous study populations complicate the interpretation of the results. Some studies include a variety of benign colorectal diseases in addition to colorectal cancer..$^{5-8}$ Diverse age cutoffs such as 65 years, ${ }^{9} 70$ years, ${ }^{10} 75$ years, ${ }^{11}$ and 80 years ${ }^{12}$ have also been used when defining elderly patients.

In octogenarian and nonagenarian patients, it is important to identify who would benefit from elective colorectal cancer resection. To date, there are few studies focusing on surgical outcomes in octogenarian and nonagenarian patients with colorectal cancer. ${ }^{13-16}$ Moreover, there is only one populationbased study investigating factors associated with 1-year mortality. ${ }^{13}$ Thus, the primary objective of this study was to identify the factors affecting 30-day postoperative complications and 1-year mortality after surgery for colorectal cancer in octogenarians and nonagenarians.

\section{Methods}

\section{Patients}

Between 2005 and 2014, 204 consecutive patients aged $\geq 80$ years who underwent major colorectal resection for colorectal cancer were included in the study. Eligibility criteria were histologically confirmed colorectal cancer and elective colectomy/proctectomy with or without metastasectomy. Patients undergoing nonresectional or bypass procedures or emergency operation for colorectal cancer were excluded. Patients were also excluded if they had histories of any type of previous abdominal malignancy. This retrospective clinical cohort study was performed at a university hospital according to the Strengthening the Reporting of Observational Studies in Epidemiology (STROBE) guidelines ${ }^{17}$ and the principles expressed in the Declaration of Helsinki. All participants provided their written informed consent, and this study was approved by the Institutional Review Board of Wonju Severance Christian Hospital (YWMR-15-5-021).

\section{Study objectives}

The primary objective was to identify the factors affecting 30 -day postoperative complications and 1-year mortality after surgery for colorectal cancer in octogenarians and nonagenarians.

\section{Preoperative chemoradiation therapy, surgery, adjuvant therapy, and postoperative surveillance}

Patients with rectal cancer who were diagnosed with clinical stage T3 or T4 and/or node-positive disease underwent preoperative chemoradiation therapy. A long course schedule included a total of 50.4 Gy of radiation and fluoropyrimidine-based chemotherapy. ${ }^{18,19}$ Surgery was performed after standardized preoperative preparations. ${ }^{20}$ Complete mesocolic excision for colon cancer and total mesorectal excision for rectal cancer were performed by two experienced colorectal surgeons. Overall treatment scheme, such as mestastasectomy and chemotherapy, was decided on the basis of weekly, multidisciplinary team discussions.

After recovery from surgery, all patients with stage II, III, and IV disease were recommended to receive chemotherapy according to National Comprehensive Cancer Network (NCCN) guidelines. ${ }^{21}$ Chemotherapy regimens included fluoropyrimidine (fluorouracil with folinic acid or capecitabine) alone or in combination with oxaliplatin (FOLFOX)/ irinotecan (FOLFIRI). Targeted agents such as cetuximab and bevacizumab were used if indicated. Adjuvant radiation was used for patients with stage II and III rectal cancer. Radiation treatment consisted of 50.4 to 54 Gy of radiation dose in 28 to 30 fractions. All postoperative patients were registered in a dedicated colorectal database and followed at 3- or 6-month intervals for the first 5 years and then yearly thereafter. Patients in this study were followed until death or September 30, 2014.

\section{Outcome variables}

Patient's age at the time of admission was calculated based on the birth date. Octogenarian refers to a patient who is 80 to 89 years old, and nonagenarian to a patient who is 90 to 99 years old. Postoperative surgical complications were defined as the events that required additional treatment within 30 days after surgery. Severity of surgical complications was evaluated based on the Clavien-Dindo classification. ${ }^{22}$ One-year mortality was defined as the all-cause deaths that occurred within 1 year after surgery. Length of hospital stay was defined as the number of nights from the date of surgery to discharge. Conversion to open surgery was defined as the completion of planned surgical procedures using a conventional laparotomy incision. Outcome variables such as intensive care unit (ICU) care or blood transfusions were included if they were required within 48 hours after index surgery. 
Binary cutoffs of continuous variables such as operative time, blood loss, hemoglobin, and albumin level were decided based on the published literature. ${ }^{23-26}$ Long operative time ( $\geq 300$ minutes), ${ }^{23}$ greater blood loss $(\geq 150 \mathrm{~mL}),{ }^{24}$ and moderate-to-severe anemia $(\mathrm{Hb}<10 \mathrm{~g} / \mathrm{dL})^{25}$ were associated with higher risk of postoperative complications following colorectal surgery. Lower albumin level $(3.4 \mathrm{~g} / \mathrm{dL})^{26}$ was associated with poor oncologic outcomes in colorectal cancer patients.

\section{Statistical analysis}

All statistical analyses were performed with IBM SPSS Statistics for Windows, version 21.0 (IBM Corporation, Armonk, NY, USA) and MedCalc Statistical Software version 15.2.2 (MedCalc Software bvba, Ostend, Belgium). Categorical variables were described by frequencies and percentages and compared using chi-square test or Fisher's exact test as appropriate. Continuous variables were described as mean and standard deviation and analyzed by Student's $t$-test. Factors associated with 30-day complications were assessed by logistic regression analysis. Factors associated with 1-year mortality were analyzed by Cox proportional hazard model. A $P$-value $<0.05$ was considered statistically significant.

Univariable logistic regression analysis was performed with all variables, and variables with a $P$-value $<0.05$ (age, American Society of Anesthesiologists [ASA] score, laparoscopy, combined surgery, hemoglobin, and albumin) were used for multivariable analysis. Tumor location was also used for analysis, as rectal cancer surgery is a well-known risk factor for postoperative complications. ${ }^{27}$ Multivariable logistic regression analysis was performed by forward stepwise selection of variables. Univariable Cox proportional hazard model analysis was performed with all variables, and variables with a $P$-value $<0.05$ (ASA score, pathological tumor-nodemetastasis [pTNM], and 30-day complication) were adopted for multivariable analysis. In addition, age and tumor location were used for analysis as older age and rectal cancer were well-known risk factors for unfavorable survival. ${ }^{21,28}$ Multivariable Cox proportional hazard model analysis was performed by forward stepwise selection of variables.

\section{Results}

\section{Patient characteristics}

Mean age was $84( \pm 4)$ years (range: 80 to 99 years). The total of 204 patients consisted of patients aged 80 to 89 years $(n=181,89 \%)$ and patients over 90 years $(n=23,11 \%)$. One hundred patients were male $(49 \%)$, and 52 patients had an ASA score $\geq 3$ (25\%). Fifty-five patients had multiple comorbidities (27\%). In terms of tumor location, 110 patients had colon cancer (54\%), and 94 patients had rectal cancer (46\%). Open surgery was performed in 80 patients $(39 \%)$, and laparoscopy was performed in 124 (61\%). Conversion to open surgery occurred in ten patients (8.1\%). Among the 29 patients with TNM stage IV disease, nine underwent metastasectomy including liver $(n=6,2.9 \%)$, vagina wall $(n=2,1.0 \%)$, and bladder $(n=1,0.5 \%)$. Laboratory tests at the time of initial diagnosis showed that mean hemoglobin $(\mathrm{Hb})$ level was $11.7( \pm 2.2) \mathrm{g} / \mathrm{dL}$ and mean albumin level was $3.9( \pm 0.4) \mathrm{g} / \mathrm{dL}$. Detailed patient characteristics are presented in Tables 1 and 2.

Median follow-up duration was 23.3 months (range: 0.1-118.7 months). Fifty-seven patients $(27.9 \%)$ had $<1$-year of follow-up. Eight patients were lost to follow-up, and all were confirmed dead based on the national health insurance service data. However, the exact reasons for death were not identified in the lost follow-up patients.

\section{Details of combined surgeries}

Combined surgery was performed in 32 patients (16\%). Liver resection was most common $(n=7,3.4 \%)$ followed by uterus $(n=6,2.9 \%)$, colon $(n=4,2.0 \%)$, ovary $(n=4)$, and gastric resection $(n=4)$.

\section{Short-term outcomes}

Mean operative time was $188( \pm 77)$ minutes, and mean intraoperative blood loss was $127( \pm 204) \mathrm{mL}$. Postoperative complication within 30 days after surgery occurred in 54 patients $(26 \%)$ and 30-day mortality occurred in five patients (2\%). Specifically, pulmonary complication was most common $(n=17)$, followed by wound $(n=15)$ and anastomotic complications $(n=6)$. ICU care was required in 94 (46\%), and blood transfusion was done in 72 (35\%) patients. Mean time to soft diet was $6( \pm 3)$ days, and mean length of hospital stay was $14( \pm 10)$ days (Table 3$)$.

\section{Factors associated with 30-day postoperative complications}

Based on multivariable logistic regression analysis, independent risk factors affecting 30-day postoperative complications were older age ( $\geq 90$ years, hazard ratio [HR] with $95 \%$ confidence interval $[\mathrm{CI}]=4.95$ [1.69-14.47], $P=0.004$ ), an ASA score $\geq 3$ r (HR with $95 \% \mathrm{CI}=4.19$ [1.8-9.74], $P=0.001)$, performance of combined surgery (HR with 95\% CI $=3.1$ [1.13-8.46], $P=0.028$ ), lower hemoglobin level $(<10 \mathrm{~g} / \mathrm{dL}$, HR with $95 \% \mathrm{CI}=7.56$ 
Table I Patient characteristics $(n=204)$

\begin{tabular}{|c|c|}
\hline Variables & $\mathbf{N}(\%)$ or mean $( \pm \mathrm{SD})$ \\
\hline Age (continuous) (years) & $84( \pm 4)$ \\
\hline \multicolumn{2}{|l|}{ Age (binary) } \\
\hline $80-89$ years old & I8I (89\%) \\
\hline 90-99 years old & $23(11 \%)$ \\
\hline \multicolumn{2}{|l|}{ Sex } \\
\hline Male & $100(49 \%)$ \\
\hline Body mass index $\left(\mathrm{kg} / \mathrm{m}^{2}\right)$ & $23( \pm 4)$ \\
\hline ASA score $(\geq 3)$ & $52(25 \%)$ \\
\hline \multicolumn{2}{|l|}{ Comorbidity } \\
\hline Diabetes & $42(21 \%)$ \\
\hline Cardiac disease & $123(60 \%)$ \\
\hline Pulmonary disease & 31 (I5\%) \\
\hline Kidney disease & $2(1 \%)$ \\
\hline Liver disease & $5(2 \%)$ \\
\hline Two or more comorbidities & $55(27 \%)$ \\
\hline Preoperative chemoradiation $(+)$ & $8(4 \%)$ \\
\hline \multicolumn{2}{|l|}{ Tumor location } \\
\hline Colon & $110(54 \%)$ \\
\hline Rectum & $94(46 \%)$ \\
\hline \multicolumn{2}{|l|}{ Types of operation } \\
\hline Abdominoperineal resection, Hartmann & $24(12 \%)$ \\
\hline Low anterior resection & $75(37 \%)$ \\
\hline Left colectomy & $48(24 \%)$ \\
\hline Subtotal colectomy & $5(2 \%)$ \\
\hline Right colectomy & $47(23 \%)$ \\
\hline Other & $5(2 \%)$ \\
\hline \multicolumn{2}{|l|}{ Surgical approach } \\
\hline Open surgery & $80(39 \%)$ \\
\hline Laparoscopy & $124(61 \%)$ \\
\hline Conversion to open surgery $(+)$ & $10(8.1 \%)$ \\
\hline \multicolumn{2}{|l|}{ Metastasectomy $(-)$ and organs } \\
\hline Liver & $9(4.4 \%)$ \\
\hline Lung & $5(2.5 \%)$ \\
\hline Peritoneum & $3(1.5 \%)$ \\
\hline Bone & $2(1.0 \%)$ \\
\hline Lung, liver, and bone & $\mathrm{I}(0.5 \%)$ \\
\hline \multicolumn{2}{|l|}{ Metastasectomy $(+)$ and organs } \\
\hline Liver & $6(2.9 \%)$ \\
\hline Vagina wall & $2(1.0 \%)$ \\
\hline Bladder & $\mathrm{I}(0.5 \%)$ \\
\hline
\end{tabular}

Abbreviations: SD, standard deviation; ASA, American Society of Anesthesiologists.

[3.07-18.63], $P<0.001)$, and lower albumin level $(<3.4 \mathrm{~g} / \mathrm{dL}$, HR with $95 \% \mathrm{CI}=3.72$ [1.43-9.69], $P=0.007$ ). Rectal primary tumor (HR with $95 \% \mathrm{CI}=2.22[0.97-5.04], P=0.058$ ) and the use of laparoscopy (HR with $95 \% \mathrm{CI}=0.77$ [0.35-1.7], $P=0.518$ ) were not independent risk factors for postoperative complications (Table 4).

\section{Factors associated with I-year mortality}

Based on multivariable Cox proportional hazard model analysis, an ASA score $\geq 3$ (HR with $95 \% \mathrm{CI}=2.72$ [1.15-6.46], $P=0.023$ ), TNM stage IV (HR with 95\% $\mathrm{CI}=3.47$ [1.44-8.39], $P=0.006$ ), and occurrence of postoperative complications (HR with $95 \% \mathrm{CI}=4.42$ [1.39-14.09],
Table 2 Pathological and laboratory data $(n=204)$

\begin{tabular}{|c|c|}
\hline Variables & $\mathbf{N}(\%)$ or mean $( \pm$ SD) \\
\hline \multicolumn{2}{|l|}{ PTNM } \\
\hline I & $35(17 \%)$ \\
\hline ॥ & $66(32 \%)$ \\
\hline III & $74(36 \%)$ \\
\hline IV & $29(14 \%)$ \\
\hline Retrieved lymph nodes (number) & $20( \pm 9)$ \\
\hline \multicolumn{2}{|l|}{ Histologic grade } \\
\hline G3, other & $20(10 \%)$ \\
\hline Tumor size $(\mathrm{cm})$ & $5( \pm 2)$ \\
\hline \multicolumn{2}{|l|}{ Laboratory data ${ }^{a}$ (reference value) } \\
\hline White blood cell count (4.0-I0.0) (E9/L) & $7.5( \pm 3.1)$ \\
\hline Hemoglobin $(\mid 3.5-17.0)(\mathrm{g} / \mathrm{dL})$ & $11.7( \pm 2.2)$ \\
\hline Platelet $(165-360)(\mathrm{E} 9 / \mathrm{L})$ & $299( \pm 112)$ \\
\hline Neutrophil (I.8-7.5) (E9/L) & $5( \pm 3)$ \\
\hline Lymphocyte (I.0-2.8) (E9/L) & $1.7( \pm 0.7)$ \\
\hline C-reactive protein $(<0.30)(\mathrm{mg} / \mathrm{dL})$ & $\mathrm{I} .7( \pm 3.2)$ \\
\hline Albumin $(3.2-5.5)(\mathrm{g} / \mathrm{dL})$ & $3.9( \pm 0.4)$ \\
\hline
\end{tabular}

Note: ${ }^{2}$ alues at the time of initial diagnosis.

Abbreviations: SD, standard deviation; PTNM, pathological tumor-node-metastasis.

$P=0.012)$ were significant prognostic factors for 1 -year mortality. Age $\geq 90$ years (HR with $95 \% \mathrm{CI}=0.23$ [0.05-1.03], $P=0.054$ ) and rectal primary cancer (HR with $95 \% \mathrm{CI}=1.09$ [0.39-3.06], $P=0.873$ ) did not influence 1-year mortality significantly (Table 5).

Table 3 Short-term outcomes $(n=204)$

\begin{tabular}{ll}
\hline Variables & $\begin{array}{l}\text { N (\%) or mean } \\
( \pm \mathbf{S D})\end{array}$ \\
\hline Operative time (minutes) & $188( \pm 77)$ \\
Estimated blood loss $(\mathrm{mL})$ & $127( \pm 204)$ \\
30-day complication $(+)$ & $54(26 \%)$ \\
30-day mortality $(+)$ & $5(2 \%)$ \\
Clavien-Dindo score $\geq 3$ & $22(11 \%)$ \\
Type of complication & a \\
Pulmonary & 17 \\
Wound & 15 \\
Leakage & 6 \\
Urinary & 5 \\
Bleeding & 5 \\
Cardiac & 4 \\
lleus & 3 \\
Other & 6 \\
Intensive care unit admission $(+)$ & $94(46 \%)$ \\
Blood transfusion $(+)$ & $72(35 \%)$ \\
Time to soft diet (days) & $6( \pm 3)$ \\
Hospital stay (days) & $14( \pm 10)$ \\
Postoperative chemotherapy $(+)$ & $82(40 \%)$ \\
Chemotherapy regimen & \\
Fluoropyrimidine & $75(37 \%)$ \\
FOLFX & $5(2 \%)$ \\
FOLFIRI & $2(1 \%)$ \\
Time to chemotherapy initiation (days) & $38( \pm 10)$ \\
\hline Not &
\end{tabular}

Note: a Eight of 204 patients (3.9\%) had more than one type of complication.

Abbreviations: SD, standard deviation; FOLFOX, folinic acid, fluorouracil, oxaliplatin; FOLFIRI, folinic acid, fluorouracil, irinotecan. 
Table 4 Factors associated with 30-day postoperative complications in logistic regression analysis $(n=204)$

\begin{tabular}{|c|c|c|c|c|}
\hline \multirow[t]{2}{*}{ Variables } & \multicolumn{2}{|l|}{ Univariable } & \multicolumn{2}{|l|}{ Multivariable } \\
\hline & HR (95\% Cl) & $P$-value & HR (95\% CI) & $P$-value \\
\hline \multicolumn{5}{|l|}{ Age (years) } \\
\hline$\geq 90$ vs $<90$ & $4.44(1.8 I-10.86)$ & 0.001 & $4.95(1.69-14.47)$ & 0.004 \\
\hline \multicolumn{5}{|l|}{ Sex } \\
\hline Male & $1.17(0.63-2.17)$ & 0.627 & NA & \\
\hline \multicolumn{5}{|l|}{ ASA score } \\
\hline$\geq 3$ & $4.43(2.24-8.75)$ & $<0.001$ & $4.19(1.8-9.74)$ & 0.001 \\
\hline \multicolumn{5}{|l|}{$\mathrm{BMI}\left(\mathrm{kg} / \mathrm{m}^{2}\right)$} \\
\hline$\geq 30$ & I.2(0.3-4.82) & 0.796 & NA & \\
\hline \multicolumn{5}{|l|}{ Tumor location } \\
\hline Rectum & I.0I (0.54-I.89) & 0.970 & $2.22(0.97-5.04)$ & 0.058 \\
\hline \multicolumn{5}{|l|}{ Laparoscopy } \\
\hline$(+)$ & $0.49(0.26-0.93)$ & 0.028 & $0.77(0.35-1.7)$ & 0.518 \\
\hline \multicolumn{5}{|c|}{ Combined surgery } \\
\hline$(+)$ & $3.01(1.38-6.57)$ & 0.006 & $3.1(1.13-8.46)$ & 0.028 \\
\hline \multicolumn{5}{|c|}{ Operative time (minutes) } \\
\hline$\geq 300$ & $1.3(0.38-4.44)$ & 0.672 & NA & \\
\hline \multicolumn{5}{|l|}{ Blood loss (mL) } \\
\hline$\geq 150$ & $1.22(0.52-2.86)$ & 0.653 & NA & \\
\hline \multicolumn{5}{|c|}{ Hemoglobin $(\mathrm{g} / \mathrm{dL})^{\mathrm{a}}$} \\
\hline$\geq 10$ vs $<10$ & $6.21(2.94-13.13)$ & $<0.001$ & $7.56(3.07-18.63)$ & $<0.001$ \\
\hline \multicolumn{5}{|l|}{ Albumin $(\mathrm{g} / \mathrm{dL})^{\mathrm{a}}$} \\
\hline$\geq 3.4$ vs $<3.4$ & 4.5 (2.07-9.79) & $<0.001$ & $3.72(1.43-9.69)$ & 0.007 \\
\hline
\end{tabular}

Note: avalues at the time of initial diagnosis.

Abbreviations: HR, hazard ratio; Cl, confidence interval; NA, not applied; ASA, American Society of Anesthesiologists; BMI, body mass index.

Table 5 Factors associated with I-year mortality in Cox proportional hazard model $(\mathrm{n}=204)$

\begin{tabular}{|c|c|c|c|c|}
\hline \multirow[t]{2}{*}{ Variables } & \multicolumn{2}{|l|}{ Univariable } & \multicolumn{2}{|l|}{ Multivariable } \\
\hline & HR (95\% Cl) & $P$-value & HR (95\% Cl) & $P$-value \\
\hline \multicolumn{5}{|l|}{ Age (years) } \\
\hline$\geq 90$ vs $<90$ & $1.5(0.35-6.35)$ & $0.58 I$ & $0.23(0.05-1.03)$ & 0.054 \\
\hline \multicolumn{5}{|l|}{ Sex } \\
\hline Male & $1.75(0.78-3.92)$ & 0.175 & NA & \\
\hline \multicolumn{5}{|l|}{ ASA score } \\
\hline$\geq 3$ & $2.31(1.06-5.04)$ & 0.035 & $2.72(1.15-6.46)$ & 0.023 \\
\hline \multicolumn{5}{|l|}{ BMI $\left(\mathrm{kg} / \mathrm{m}^{2}\right)$} \\
\hline$\geq 30$ & $1.41(0.19-10.4)$ & 0.737 & NA & \\
\hline \multicolumn{5}{|l|}{ Tumor location } \\
\hline Rectum & $1.35(0.62-2.91)$ & 0.450 & $1.09(0.39-3.06)$ & 0.873 \\
\hline \multicolumn{5}{|l|}{ pTNM } \\
\hline IV vs I, II, III & $4.15(1.88-9.15)$ & $<0.001$ & $3.47(1.44-8.39)$ & 0.006 \\
\hline \multicolumn{5}{|l|}{ Laparoscopy } \\
\hline$(+)$ & $0.47(0.22-1.02)$ & 0.056 & NA & \\
\hline \multicolumn{5}{|c|}{ Hemoglobin $(\mathrm{g} / \mathrm{dL})^{\mathrm{a}}$} \\
\hline$<10$ vs $\geq 10$ & $1.68(0.7-3.99)$ & 0.243 & NA & \\
\hline \multicolumn{5}{|l|}{ Albumin $(g / d L)^{a}$} \\
\hline$<3.4$ vs $\geq 3.4$ & $1.28(0.48-3.4)$ & 0.619 & NA & \\
\hline \multicolumn{5}{|c|}{ 30-day complication } \\
\hline$(+)$ & $3.63(1.68-7.85)$ & 0.001 & $4.42(1.39-14.09)$ & 0.012 \\
\hline
\end{tabular}

Note: ${ }^{\text {a }}$ alues at the time of initial diagnosis.

Abbreviations: HR, hazard ratio; Cl, confidence interval; NA, not applied; ASA, American Society of Anesthesiologists; BMI, body mass index; pTNM, pathological tumornode-metastasis. 


\section{Discussion}

The major findings of this study were that multiple risk factors were associated with 30-day postoperative complications such as advanced chronological age (aged $\geq 90$ years), poor functional status (ASA score $\geq 3$ ), invasiveness of surgical procedure (performance of combined surgery), presence of anemia $(\mathrm{Hb}<10 \mathrm{~g} / \mathrm{dL})$, and poor nutritional status (albumin $<3.4 \mathrm{~g} / \mathrm{dL}$ ). To prevent the postoperative complications, the surgeon and the surgical team should consider multidimensional aspects preoperatively. Adverse prognostic factors affecting 1-year mortality were poor functional status (ASA score $\geq 3$ ), advanced disease stage (TNM stage IV), and occurrence of 30-day postoperative complications. To decrease 1-year mortality, avoidance of postoperative complications and careful patient selection by considering preoperative clinical features (ASA score $\geq 3$ and TNM stage IV) are important.

There is paucity in literature concerning surgical outcomes after colorectal cancer surgery in octogenarians and nonagenarians (Table 6). Colon and rectal cancer surgeries characterized by complete mesocolic excision ${ }^{29}$ and total mesorectal excision ${ }^{30}$ are quite different from surgery for benign colorectal diseases. Emergency surgery carries higher risk of postoperative morbidity and mortality. ${ }^{31}$ Accordingly, in this era of an aging society, it is important to investigate surgical outcomes in octogenarian and nonagenarian patients. To the best of our knowledge, this is the second largest study ${ }^{13}$ investigating octogenarian and nonagenarian patients undergoing elective surgery for colorectal cancer.

\section{Factors associated with 30-day postoperative complications}

Various factors were associated with the occurrence of postoperative complications in octogenarian and nonagenarian patients. Previous studies reported postoperative complication rates of $12 \%$ to $27.5 \%$ after colorectal cancer surgery in octogenarians and nonagenarians, ${ }^{14-16}$ and the rate in this study was $26 \%$. The aging process diminishes physiologic functional reserves in vital organs; therefore, chronological age itself is an established risk factor. Turrentine et al ${ }^{32}$ investigated 7,696 patients undergoing major general and vascular surgical procedures and observed that the postoperative morbidity rate was $49 \%$ in octogenarians and $61 \%$ in nonagenarians. Similar findings were obtained in this study $(22.7 \%$ postoperative complication rate in octogenarians and $56.5 \%$ in nonagenarians). Patient functional status and comorbidity are important factors when considering surgery. The ASA score is a widely adopted classification that indicates severity

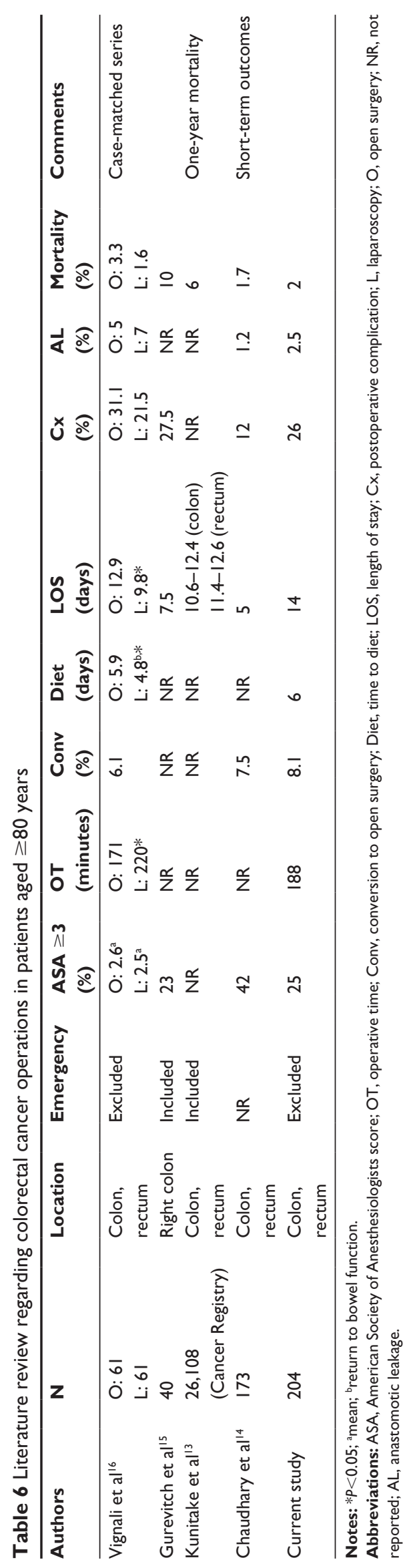


of systemic illness. Previous studies investigating colorectal cancer surgery in octogenarians and nonagenarians included $23 \%{ }^{15}$ and $42 \%{ }^{14}$ of patients with ASA score $\geq 3$ and this study included $25 \%$. Higher ASA score has been reported as a significant predictor for postoperative morbidity and mortality, ${ }^{33}$ and we also observed that ASA score $\geq 3$ was an independent risk factor for postoperative complications. Invasiveness of the surgical procedure is also related to postoperative morbidity. Octogenarian patients undergoing major resections for lung, esophageal, and pancreas cancer showed different postoperative morbidity rates according to the type of surgeries. ${ }^{34}$ The impact of combined surgery on surgical outcomes has not been reported in octogenarians. ${ }^{5-16}$ In this study, combined surgery was performed in $16 \%$ of patients and included liver, uterus, or colon resection; combined surgery was found to be an independent risk factor for complications. Anemia is a frequent clinical feature of colorectal malignancy and is closely related to older age and comorbidities. ${ }^{35}$ Patients with anemia are susceptible to nosocomial infections and adverse postoperative events. ${ }^{25}$ In this study, $19 \%$ of patients had $\mathrm{Hb}<10 \mathrm{~g} / \mathrm{dL}$, and the postoperative complication rate was $19 \%$ in $\mathrm{Hb} \geq 10 \mathrm{~g} / \mathrm{dL}$ group and 59\% in $\mathrm{Hb}<10$ group. Serum albumin level indicates patient's nutritional status and elderly patients are at particular risk of poor nutritional status. Low albumin level correlates with the occurrence of postoperative complications $^{36}$ as was confirmed in our study. In this study, 16\% of patients had albumin $\leq 3.4 \mathrm{~g} / \mathrm{dL}$, and the postoperative complication rate was $21 \%$ in albumin $>3.4 \mathrm{~g} / \mathrm{dL}$ group and $55 \%$ in albumin $\leq 3.4 \mathrm{~g} / \mathrm{dL}$ group.

\section{Factors associated with I-year mortality} ASA score $\geq 3$, TNM stage IV, and occurrence of postoperative complications were unfavorable risk factors for 1-year mortality in this study. Higher ASA score ${ }^{37}$ and advanced TNM stage ${ }^{38}$ are well-known prognostic factors. The presence of postoperative complications delays patient recovery and worsens oncologic outcomes. ${ }^{39}$ The exact mechanism is unclear, but omission of adjuvant treatment or direct impairment of physical status such as heart failure due to complication severity has been suggested as potential causes for poor survival. ${ }^{40}$ Thus, surgeons should be aware of the negative impact of postoperative complications on 1-year mortality. A high proportion of patients (40\%) underwent adjuvant chemotherapy. In our institution, patients were discussed at weekly multidisciplinary team meetings and adjuvant treatment was based on NCCN guidelines. If performance status was acceptable, we actively encouraged adjuvant treatment.

\section{Limitations}

This study has limitations in the retrospective study design and small sample size from a single institution. These factors might diminish the statistical power of the study and compromise the generalizability of the current findings. In the octogenarian patient group, 41 patients $(23 \%)$ had ASA score $\geq 3$; on the other hand, eleven patients (48\%) had ASA score $\geq 3$ in the nonagenarian group. However, there were only 23 nonagenarian patients, comprising $11 \%$ of the study population. Accordingly, we could not draw definitive conclusions from our small study sample. Also, due to the large time span of this study, some treatment-related factors changed during the study period. For example, laparoscopy has been popularized and a fast-track protocol has been selectively adopted. However, we could not consider all these factors in the current analysis due to the small study size. Finally, the retrospective nature of the study does not allow us to specify whether the cause of death is cancer related or not. However, this is the second largest series to investigate surgical outcomes in octogenarian and nonagenarian patients with colorectal cancer.

\section{Conclusion}

In summary, this study identified various factors affecting 30-day postoperative complications and 1-year mortality after surgery for colorectal cancer in octogenarians and nonagenarians. To prevent postoperative complications, multidimensional aspects should be considered preoperatively, including chronological age, physical functional status based on ASA score, whether to perform combined surgical procedure, presence of anemia, and nutritional status based on serum albumin level. Inherent preoperative features such as ASA score $\geq 3$ and TNM stage IV negatively influenced 1 -year mortality. However, our results suggest that avoidance of 30-day postoperative complications may decrease 1-year mortality; thus, surgeons should focus on meticulous surgical technique and comprehensive postoperative care. In the future, a prospective study with a larger cohort would be helpful to confirm the current findings of this study.

\section{Acknowledgment}

The authors thank Dr Bo Ra Kim for management of the colorectal database, without which this study would not have been possible.

\section{Author contributions}

YWK conceived and designed the experiments, performed the experiments, and analyzed the data. IYK and YWK contributed reagents/materials/analysis tools and YWK wrote the 
paper. All authors contributed toward data analysis, drafting and critically revising the paper and agree to be accountable for all aspects of the work.

\section{Disclosure}

The authors report no conflicts of interest in this work.

\section{References}

1. Mathers CD, Stevens GA, Boerma T, White RA, Tobias MI. Causes of international increases in older age life expectancy. Lancet. 2015; 385(9967):540-548.

2. Ferlay J, Soerjomataram I, Dikshit R, et al. Cancer incidence and mortality worldwide: sources, methods and major patterns in GLOBOCAN 2012. Int J Cancer. 2015;136(5):Epub 2014 Oct 9.

3. Kahn KL, Adams JL, Weeks JC, et al. Adjuvant chemotherapy use and adverse events among older patients with stage III colon cancer. JAMA. 2010;303(11):1037-1045.

4. Kim YW, Kim IY. The role of surgery for asymptomatic primary tumors in unresectable stage IV colorectal cancer. Ann Coloproctol. 2013; 29(2):44-54.

5. Lian L, Kalady M, Geisler D, Kiran RP. Laparoscopic colectomy is safe and leads to a significantly shorter hospital stay for octogenarians. Surg Endosc. 2010;24(8):2039-2043.

6. Seshadri PA, Mamazza J, Schlachta CM, Cadeddu MO, Poulin EC. Laparoscopic colorectal resection in octogenarians. Surg Endosc. 2001; 15(8):802-805.

7. Stewart BT, Stitz RW, Lumley JW. Laparoscopically assisted colorectal surgery in the elderly. Br J Surg. 1999;86(7):938-941.

8. Wise WE Jr, Padmanabhan A, Meesig DM, Arnold MW, Aguilar PS, Stewart WR. Abdominal colon and rectal operations in the elderly. Dis Colon Rectum. 1991;34(11):959-963.

9. Kennedy GD, Rajamanickam V, O'Connor ES, et al. Optimizing surgical care of colon cancer in the older adult population. Ann Surg. 2011;253(3):508-514.

10. Frasson M, Braga M, Vignali A, Zuliani W, Di Carlo V. Benefits of laparoscopic colorectal resection are more pronounced in elderly patients. Dis Colon Rectum. 2008;51(3):296-300.

11. Scheidbach H, Schneider C, Hügel O, Yildirim C, Lippert H, Kockerling F. Laparoscopic surgery in the old patient: do indications and outcomes differ? Langenbecks Arch Surg. 2005;390(4):328-332.

12. Roviello F, Marrelli D, De Stefano A, Messano A, Pinto E, Carli A. Complications after surgery for gastric cancer in patients aged 80 years and over. Jpn J Clin Oncol. 1998;28(2):116-122.

13. Kunitake H, Zingmond DS, Ryoo J, Ko CY. Caring for octogenarian and nonagenarian patients with colorectal cancer: what should our standards and expectations be? Dis Colon Rectum. 2010;53(5):735-743.

14. Chaudhary BN, Shabbir J, Griffith JP, Parvaiz A, Greenslade GL, Dixon AR. Short-term outcome following elective laparoscopic colorectal cancer resection in octogenarians and nonagenarians. Colorectal Dis. 2012;14(6):727-730.

15. Gurevitch AJ, Davidovitch B, Kashtan H. Outcome of right colectomy for cancer in octogenarians. J Gastrointest Surg. 2009;13(1):100-104.

16. Vignali A, Di Palo S, Tamburini A, Radaelli G, Orsenigo E, Staudacher C. Laparoscopic vs. open colectomies in octogenarians: a case-matched control study. Dis Colon Rectum. 2005;48(11):2070-2075.

17. von Elm E, Altman DG, Egger M, Pocock SJ, Gotzsche PC, Vandenbroucke JP. The Strengthening the Reporting of Observational Studies in Epidemiology (STROBE) statement: guidelines for reporting observational studies. Lancet. 2007;370(9596):1453-1457.

18. Kim IY, Cha SW, Ahn JH, Kim YW. Factors affecting the restaging accuracy of magnetic resonance imaging after preoperative chemoradiation in patients with rectal cancer. Eur J Surg Oncol. 2015;41(4):493-498.

19. Kim IY, You SH, Kim YW. Neutrophil-lymphocyte ratio predicts pathologic tumor response and survival after preoperative chemoradiation for rectal cancer. BMC Surg. 2014;14(1):94.
20. Kim YW, Choi EH, Kim IY, Kwon HJ, Ahn SK. The impact of mechanical bowel preparation in elective colorectal surgery: a propensity score matching analysis. Yonsei Med J. 2014;55(5):1273-1280.

21. Kim IY, Kim BR, Kim YW. Factors affecting use and delay $(>/=8$ weeks $)$ of adjuvant chemotherapy after colorectal cancer surgery and the impact of chemotherapy-use and delay on oncologic outcomes. PLoS One. 2015;10(9):e0138720.

22. Kim IY, Kim BR, Kim YW. The impact of anastomotic leakage on oncologic outcomes and the receipt and timing of adjuvant chemotherapy after colorectal cancer surgery. Int J Surg. 2015;22:3-9.

23. Fleshman J, American Society of Colon and Rectal Surgeons. The ASCRS Textbook of Colon and Rectal Surgery. New York, NY: Springer; 2007.

24. Paolino J, Steinhagen RM. Colorectal surgery in cirrhotic patients. ScientificWorldJournal. 2014;2014:239293.

25. Muñoz M, Gómez-Ramírez S, Martín-Montañez E, Auerbach M. Perioperative anemia management in colorectal cancer patients: a pragmatic approach. World J Gastroenterol. 2014;20(8):1972-1985.

26. Gupta D, Lis CG. Pretreatment serum albumin as a predictor of cancer survival: a systematic review of the epidemiological literature. Nutr J. 2010;9:69.

27. Paun BC, Cassie S, MacLean AR, Dixon E, Buie WD. Postoperative complications following surgery for rectal cancer. Ann Surg. 2010;251(5): 807-818.

28. Park IJ, Choi GS, Lim KH, Kang BM, Jun SH. Different patterns of lymphatic spread of sigmoid, rectosigmoid, and rectal cancers. Ann Surg Oncol. 2008;15(12):3478-3483.

29. Hohenberger W, Weber K, Matzel K, Papadopoulos T, Merkel S. Standardized surgery for colonic cancer: complete mesocolic excision and central ligation - technical notes and outcome. Colorectal Dis. 2009;11(4):354-364; discussion 364-355.

30. Heald RJ, Ryall RD. Recurrence and survival after total mesorectal excision for rectal cancer. Lancet. 1986;1(8496):1479-1482.

31. Kim IY, Kim BR, Kim YW. Outcomes of laparoscopic and open surgery for colorectal cancer in the emergency setting. In Vivo. 2015;29(2): 295-300.

32. Turrentine FE, Wang H, Simpson VB, Jones RS. Surgical risk factors, morbidity, and mortality in elderly patients. J Am Coll Surg. 2006;203(6): 865-877.

33. Hamel MB, Henderson WG, Khuri SF, Daley J. Surgical outcomes for patients aged 80 and older: morbidity and mortality from major noncardiac surgery. J Am Geriatr Soc. 2005;53(3):424-429.

34. Finlayson E, Fan Z, Birkmeyer JD. Outcomes in octogenarians undergoing high-risk cancer operation: a national study. J Am Coll Surg. 2007; 205(6):729-734.

35. Schwartz RN. Anemia in patients with cancer: incidence, causes, impact, management, and use of treatment guidelines and protocols. Am J Health Syst Pharm. 2007;64(3 Suppl 2):S5-S13; quiz S28-S30.

36. Park SY, Chung JS, Kim SH, Kim YW, Ryu H, Kim DH. The safety and prognostic factors for mortality in extremely elderly patients undergoing an emergency operation. Surg Today. 2016;46(2):241-247. doi:10.1007/ s00595-015-1147-x.

37. Leonard D, Penninckx F, Laenen A, Kartheuser A. Quantitative contribution of prognosticators to oncologic outcome after rectal cancer resection. Dis Colon Rectum. 2015;58(6):566-574.

38. Kim IY, Kim BR, Kim HS, Kim YW. Differences in clinical features between laparoscopy and open resection for primary tumor in patients with stage IV colorectal cancer. Onco Targets Ther. 2015;8: 3441-3448.

39. Khuri SF, Daley J, Henderson W, et al. Risk adjustment of the postoperative mortality rate for the comparative assessment of the quality of surgical care: results of the National Veterans Affairs Surgical Risk Study. J Am Coll Surg. 1997;185(4):315-327.

40. Law WL, Choi HK, Lee YM, Ho JW. The impact of postoperative complications on long-term outcomes following curative resection for colorectal cancer. Ann Surg Oncol. 2007;14(9):2559-2566. 
Clinical Interventions in Aging

\section{Publish your work in this journal}

Clinical Interventions in Aging is an international, peer-reviewed journal focusing on evidence-based reports on the value or lack thereof of treatments intended to prevent or delay the onset of maladaptive correlates of aging in human beings. This journal is indexed on PubMed Central, MedLine,

CAS, Scopus and the Elsevier Bibliographic databases. The manuscript management system is completely online and includes a very quick and fair peer-review system, which is all easy to use. Visit http://www.dovepress. $\mathrm{com} /$ testimonials.php to read real quotes from published authors.

Submit your manuscript here: http://www.dovepress.com/clinical-interventions-in-aging-journal 